\title{
BoHV-4 immediate early 1 gene is a dispensable gene and its product is not a bone marrow stromal cell antigen 2 counteracting factor
}

\author{
Valentina Franceschi ${ }^{1}$, Antonio Capocefalo ${ }^{1}$, Sarah Jacca ${ }^{1}$, Alfonso Rosamilia ${ }^{1}$, Sandro Cavirani ${ }^{1}$, Fengwen Xu' \\ Wentao Qiao $^{2}$ and Gaetano Donofrio ${ }^{1 *}$
}

\begin{abstract}
Background: Bovine herpesvirus 4 (BoHV-4) is a gammaherpesvirus whose genome was cloned as Bacterial Artificial Chromosome (BAC) and exploited as a gene delivery vector for vaccine purposes. Although BoHV-4 genome has been completely sequenced and its open reading frames (ORFs) structurally defined in silico, most of them are not functionally characterized. In BoHV-4 genome two major immediate early genes (IE) are present, IE1 and IE2. IE2 is an essential gene because its removal from the viral genome renders the virus unable to replicate, whereas for IE1 no many functional information are available.

Results: In this work, IE1 contribution in initiating and maintaining BoHV-4 lytic replication was assessed generating

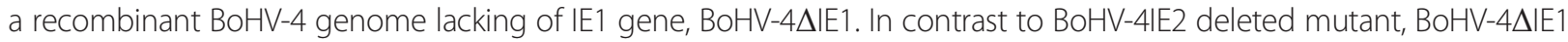
infectious replicating viral particles (IRVPS) could be reconstituted following viral DNA electroporation in permissive cells. However the titer of BoHV-4AIE1 IRVPs produced into the cell supernatant and BoHV-4AIE1 plaques size were reduced respect to BoHV-4 undeleted control. Further the impaired BoHV-4AIE1 IRVPs produced into the cell supernatant could be rescued by expressing IE1 gene product in trans, confirming the implication of IE1 in BoHV-4 Iytic replication. Next, the possible role of BoHV-4IE1 as bone marrow stromal cell antigen 2 (BST-2) counteracting factor, as hypothesized by IE1 amino-terminal gene product homology with Kaposi Sarcoma Associated Herpesvirus (KSHV) K5, was excluded too.
\end{abstract}

Conclusions: Although the real function of BoHV-4IE1 is still elusive, a new BoHV-4 genome gene locus as a target site for the insertion of foreign DNA and resulting in the attenuation of the virus has been revealed. These data can be considered of relevance to improve BoHV-4 gene delivery properties.

Keywords: Bovine herpesvirus 4, Viral vector, Bacteria artificial chromosome, Immediate early gene, Gene knock-down, Impaired viral replication

\section{Background}

Bovine herpesvirus 4 (BoHV-4) is a gammaherpesvirus of the genus Rhadinovirus, and has been isolated both in healthy animals and in animals with variable diseases, from ocular discharge, conjunctivitis, dermatitis, respiratory diseases and abortion [1-3]. The pathogenic role of BoHV-4 remains unclear, even if there is increasing evidence of a secondary pathogenic role in bovine post-

\footnotetext{
* Correspondence: gaetano.donofrio@unipr.it

${ }^{1}$ Department of Medical-Veterinary Science, University of Parma, via del Taglio 10, 43126 Parma, Italy

Full list of author information is available at the end of the article
}

partum metritis [3-8]. The coding capacity of BoHV-4 has been described as well as the common and unique features of the BoHV-4 genome in comparison to those of other gammaherpesviruses. However many of BoHV-4 genes and their products have not been functionally characterized [9].

BoHV-4 gene expression cascade is similar to that of other herpesviruses and comprises Immediate Early (IE), Early (E) and Late (L) gene expression [10]. Herpesvirus IE genes are experimentally defined as those which are transcribed when cells are infected in the presence of protein synthesis inhibitor, because IE gene expression 
does not require de novo viral protein synthesis. Under this conditions, RNA transcribed from IE genes usually accumulates to higher levels than in absence of inhibitors, presumably because of the lack of feed-back inhibition. Two major BoHV-4IE RNAs were characterized early during infection in the presence of cycloheximide, IE1 and IE2 [11]. Although both of them have been well characterized in terms of gene structure, transcription and RNA post-transcriptional processing [11, 12], the only one to be functionally characterized was IE2 $[13,14]$. The generation of viral mutants targeting the IE2 locus within the BoHV-4 genome, provided the direct demonstration that BoHV-4 gene product, ORF50/Rta, is indispensable in initiating and allowing progression of BoHV-4 lytic replication $[13,14]$. In fact a recombinant BoHV-4 in which ORF50/Rta was deleted was completely unable to replicate, but was efficiently rescued, with respect to production of infectious virus and DNA replication, upon the expression of ORF50/Rta in trans [14]. Whereas as regards BoHV-4IE1 gene, it is the most abundant viral RNA transcribed in the presence of cycloheximide, though its abundance is greatly reduced in absence of inhibitor, suggesting a down regulation by newly synthesized viral proteins [11]. Since BoHV-4IE1 RNA is the major RNA found under IE conditions, it was referred to it as the major IE RNA [11]. IE1 is a spliced, 1,7 kb RNA, containing four exons and transcribed from the right to the left of BoHV-4 genome. IE1 open reading frame (ORF) codes for a protein of 285 amino acids (aa) with a predicted molecular weight of $33 \mathrm{kDa}$ and an unknown function [11]. Therefore, the purpose of the present work was to knockdown BoHV-4IE1 gene in BoHV-4 genome cloned as a $\mathrm{BAC}$, to reveal its potential contribution in initiating and maintaining BoHV-4 lytic replication.

\section{Results and discussion}

\section{Generation of a BoHV-4IE1 deleted mutant}

Although BoHV-4IE1 is simultaneously expressed along with IE2 during BoHV-4 life cycle and IE2 has a pivotal role in initiating the BoHV-4 transcriptional replication $[13,14]$, it was of interest to know if IE1 could have an essential role similarly to that observed for IE2. The main way to achieve this kind of information was to knock-down IE1 gene coding regions by heat inducible homologous recombination into the genome of BoHV-4 cloned as bacterial artificial chromosome. A targeting fragment, IE1L-KanaGalK-IE1R, containing the 2232 base-pairs (bp) KanaGalK double selecting cassette [15] flanked by two BoHV-4IE1 gene homologous sequences, was introduced between the BoHV-4 genome position 19,672 and 20,229. This insertion, comprising the full deletion of the IE1 third exon and most of the fourth exon, resulted with the elimination of the $70 \%$ of the IE1 coding regions. Many genes of BoHV-4 genome are overlapped and the coding region of a gene can also works as a regulatory region for the neighboring gene. This IE1 gene knock-down strategy allowed maintaining intact the Bo4 and Bo6 gene promoter, thus preserving their transcription and translation (data not shown). Therefore, the viral phenotype obtained from this insertion/deletion was exclusively due to BoHV-4IE1 knockdown and not contaminated by the loss of expression of the flanking genes, in this specific case Bo4 and Bo6 (Fig. 1a). To generate BoHV-4 with knocked-down IE1 gene, BoHV-4 $\triangle I E 1$, linearized pIE1L-KanaGalK-IE1R was electroporated in SW102 E. coli containing pBACBoHV-4 genome and pBAC-BoHV-4AIE1 was generated. The authenticity of the selected targeted clones were checked by PstI restriction enzyme digestion and confirmed by southern hybridization by a specific probe (Fig. 1b). Further, pBAC-BoHV-4 $\triangle$ IE1 clone stability in SW $102 \mathrm{E}$. coli, before to attempt the reconstitution of the IE1 deleted virus, was assessed by serial passages (over 20) and PstI digestion. pBAC-BoHV-4AIE1 was stable as observed by the absence of differences among the restriction profile of pBAC-BoHV-4 $\triangle \mathrm{IE} 1$ derived from different passages (Fig. 1c).

\section{BoHV-4LIE1 has an impaired replication}

Herpesvirus gene expression cascade and replication is mainly governed by the immediate early gene expression. The competence of the viral DNA genome to reconstitute Infectious Replicating Viral Particles, IRVPs, can be tested by transfecting the mutant viral genome in permissive cell lines and this is greatly facilitated if the viral genome, as is the case of BoHV-4, is cloned as a BAC. As a first approach to test the characteristics of the viral phenotype obtained from IE1 knock-down, a viral reconstitution assay was employed. BEK cells and BEKcre cells, constitutively expressing cre recombinase [16] to excise out the floxed BAC cassette from the viral genome, were electroporated with pBAC-BoHV-4, pBACBoHV-4 $\triangle \mathrm{IE} 1$ and pBAC-BoHV-4 $\triangle \mathrm{TK}$, a mutant BoHV-4 genome in which the 2232 bp KanaGalK double selectable marker was inserted into the BoHV-4 thymidine kinase (TK) gene [17-19] without interfering with the replication property of the resulting virus. Surprisingly, all three genomes could efficiently reconstitute IRVPs (Fig. 2a) and this was the first consisting indication that IE1 is not an essential gene contrarily to what it was observed for BoHV-4IE2 and gB Knock-down, which gave a complete replicating uncompetent phenotype [14, 18]. Although the viral reconstitution assay is very informative from the qualitative point of view, on the other hand it is poorly quantitative. Thus the replication kinetics of BoHV-4 $\triangle \mathrm{IE} 1$ and BoHV-4 obtained from pBAC-BoHV-4 $\triangle \mathrm{IE} 1$ and pBAC-BoHV-4 BEKcre transfected cells were compared. A slower replication, of $\sim 1 \log$, for BoHV-4AIE1 respect 

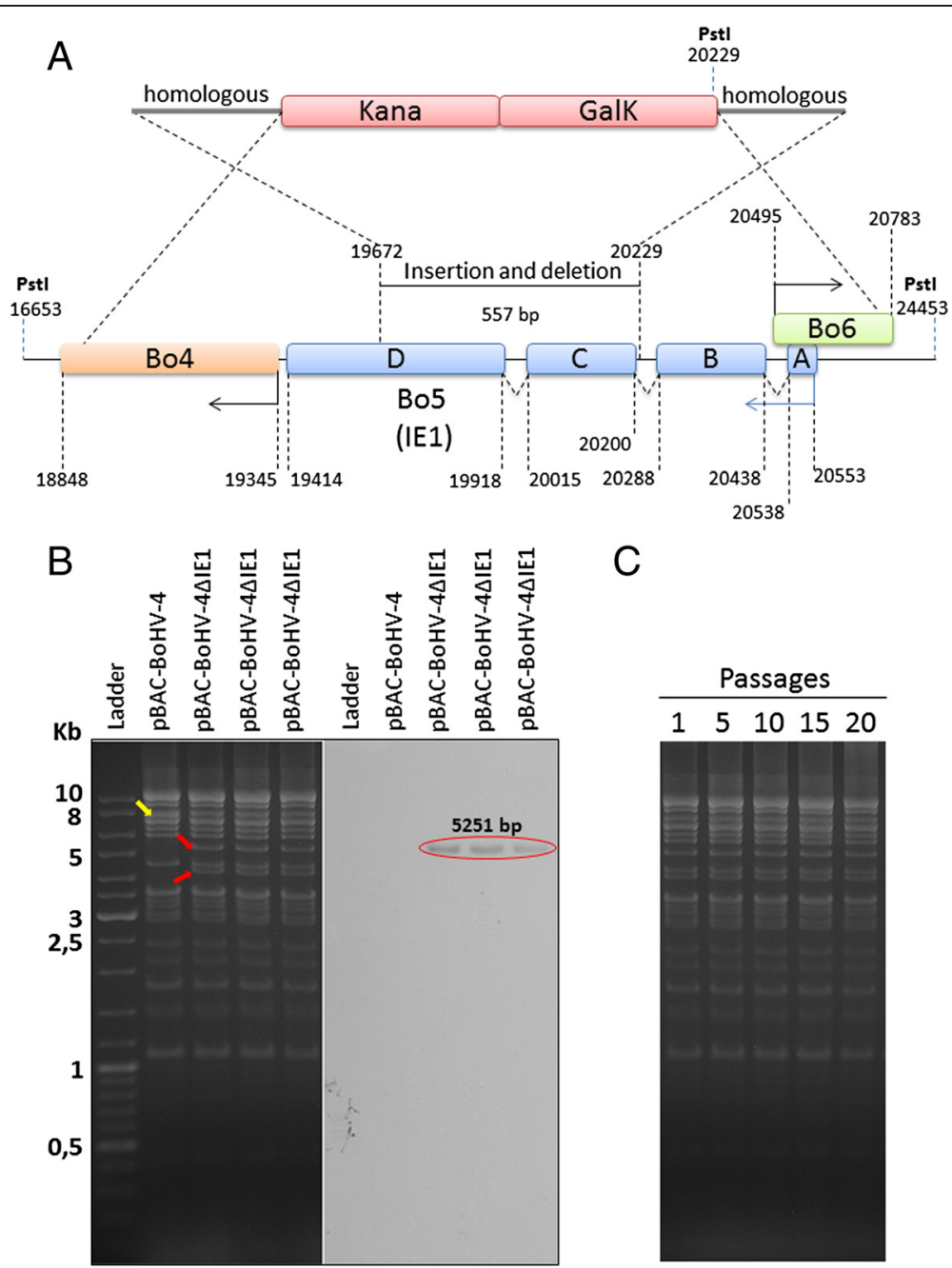

Fig. 1 Generation of BoHV-4- $\Delta \mathrm{IE} 1$. a Schematic representation (not on scale) of the overall strategy to knock-down IE1 gene in BoHV-4 genome clone in SW 102 E. coli. Bo4 (orange), Bo5 [(IE1), blue] and Bo6 (green) gene coding regions are indicated by numbers, which represent nucleotide positions within the BoHV-4 genome [based on the BoHV-4-66p347 complete genome published sequence (GenBank accession number AF318573)]. The targeting fragment (red), IE1L-KanaGalK-IE1R, flanked by two homologous sequences allowed the insertion of the double selectable marker KanaGalK between the positions 19,672 and 20,229, deleting most of the IE1 coding region but leaving intact the Bo4 and Bo6 promoters. IE1 locus possess two Pstl sites, one at the position 16,653 and one at the position 24,453, generating a fragment of $7800 \mathrm{bp}$. After targeting, a new Pstl site, delivered by the targeted vector, was introduced into the IE1 locus and thus generating three Pstl restriction sites and two Pstl digestion product, of 4224 and 5251 bp respectively. Pstl restriction enzyme digestion allowed to distinguish between targeted and untargeted clones (b), in fact the targeted clones (pBAC-BoHV-4 $\Delta \mathrm{EE} 1$ ) display two new bands (indicated by red arrows) respect to the untargeted control clone (pBAC-BoHV-4; indicated by the yellow arrow). This is further confirmed by southern blotting with a specific probe for KanaGalK (red circle). c Clonal stability of pBAC-BoHV-4AIE1 in SW 102 E. coli at passage 1, 5, 10, 15, 20 and analyzed by Pstl restriction digestion

to BoHV-4 was observed (Fig. 2b). Although IE genes are the first genes to be transcribed during the infection, their function can be protracted for the entire viral replication cycle. BoHV-4 is a Gammaherpesvirus with a slow replication cycle respect to alpha and beta herpesvirus and this is the reason why we see differences during the late infection. This data was corroborated by the reduction of the plaque size generated by BoHV-4 $\Delta \mathrm{IE} 1$ respect to BoHV-4 (Fig. 2c and d).
BoHV-4- $\Delta \mathrm{IE} 1$ impaired replication can be rescued by IE1 expressed in trans

To confirm that the impaired replication, despite of small entity $(\sim 1 \mathrm{log})$ but significant, observed for BoHV$4 \triangle I E 1$, was due to the loss of IE1 and not a mere artifact, BEK cells constitutively expressing IE1 were generated to rescue in trans the loss of IE1. IE1 ORF cDNA was obtained by PCR with an antisense primer containing a restriction site, a kozak's sequence and 


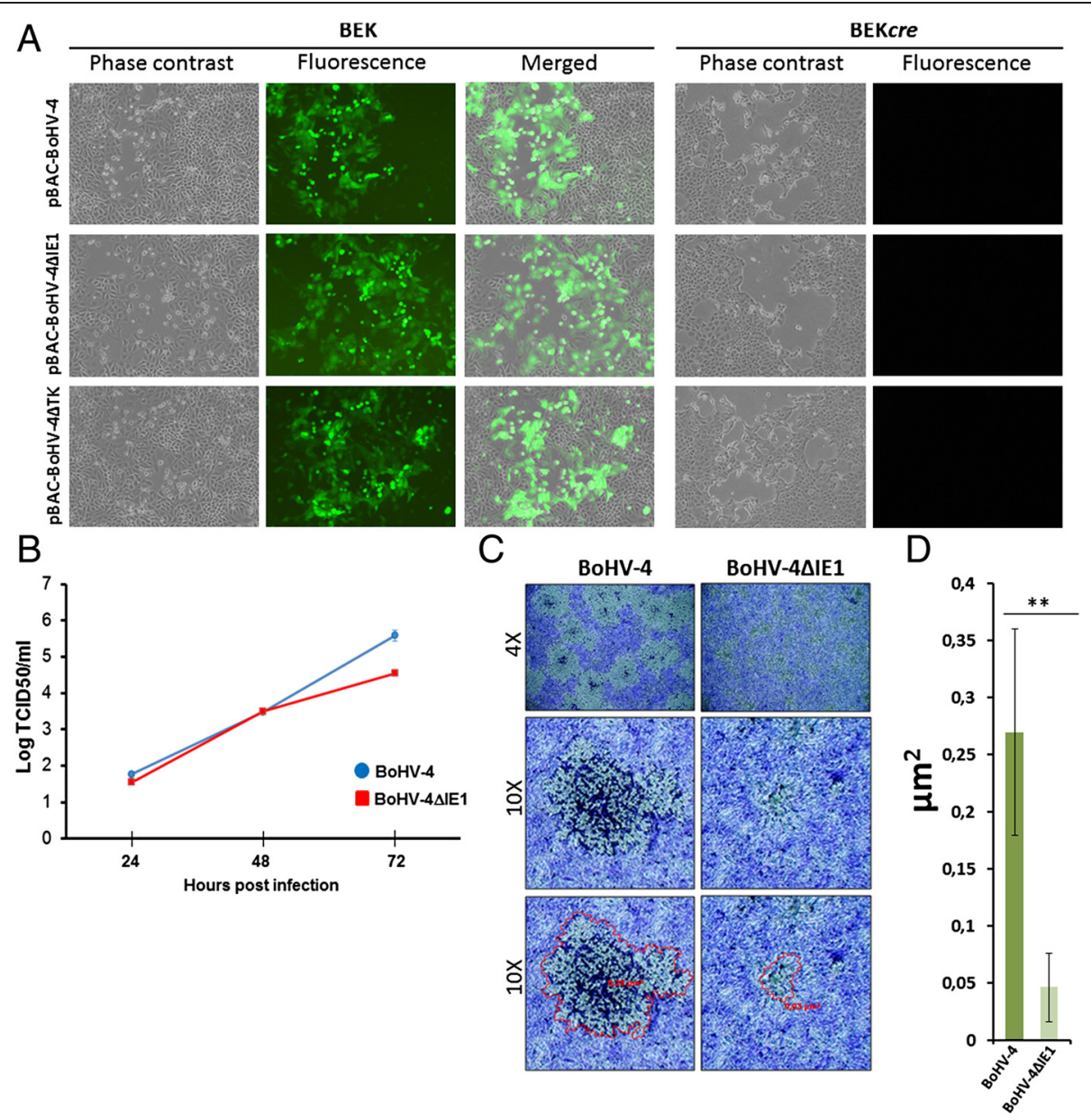

Fig. 2 Characterization of BoHV-4- $\Delta \mathrm{EE}$ 1. a Representative images (phase contrast, fluorescence and merged; 10X) of BEK and BEK expressing cre (BEKcre; in the right panel) electroporated with PBAC-BoHV-4 and PBAC-BoHV-4AIE1 DNA. CPE induced by reconstitution of IRVPs is recognizable for all three BAC viral genomes (dark pictures in fluorescence for BAC transfected BEKcre cells is due the loss of GFP expression cassette contained in the floxed BAC backbone removed by cre recombinase). The test was repeated three times always giving identical results. $\mathbf{b}$ Replication kinetics of BoHV-4LIE1 (red line) and BoHV-4 (blue line). c Representative images ( $4 \times$ and 10X) showing plaque morphology and relative plaque sizes of BoHV-4 and BoHV-4AIE1 on Vero cells. $\mathbf{d}$ The plaque sizes $\left(\mu^{2}{ }^{2}\right)$ were measured using the Axio-Vision40-V4.6.3.0 (Carl Zeiss, Imaging Solution) software program. Bars represent means \pm standard errors of 50 plaques for each virus $[(* *) P \leq 0.001)]$. Significance was measured by ANOVA

matching the first eight codons comprising the atg, and a sense primer matching the last eight codons, including the stop codon, end ending with a restriction site (Table 1; Fig. 3a). So generated IE1 ORF cDNA was sub cloned in a bicistronic expression vector provided of the CMV promoter, an internal ribosomal entry site (IRES) and a selectable marker (neo) (Fig. 3a). pCMV-IE1-IRESneo was electroporated in BEK cells and cells selected with G418 to get BEK/IE1 cells. Next, BoHV-4AIE1 and BoHV-4 replication kinetics were compared on BEK/IE1 cells. As hoped, and showed in Fig. 3b, the gap of replication between BoHV-4 $\triangle \mathrm{IE} 1$ and BoHV-4 was filled by expressing IE1 in trans. Although a revertant strain could be generated, however it was reasoned that a revertant strain is not so much different from a wild type and for this reason it was preferred the expression in trans of the mutated gene.

\section{BoHV-4IE1 is not a tethering counteracting factor}

Despite BoHV-4IE1 gene deletion gave a mild phenotype that could be rescued by BoHV-4IE1 gene expression in trans, the real function of BoHV-4IE1 gene, in the contest of viral replication, remained elusive. However from in silico study it was noticed that BoHV-4IE1 shares a conserved amino-terminal domain with the K5/K3-family gamma-2 herpesvirus plant homeo domain (PHD)/ leukemia associated protein (LAP)-finger type [20]. In a proteomics screen for new host targets of KSHV K5, it was observed that bone marrow stromal cell antigen 2 (BST-2, also called tetherin), an interferon-induced protein 
Table 1 List of primers used in that work

\begin{tabular}{ll}
\hline Primer name & 5'-3' Primer sequence \\
\hline IE1-left-sense & 5'-CCC GAA TTC CAA TTG ACA ACA TAT AAA GTC-3' \\
IE1-left-antisense & 5'-CCC GGT ACC CGA TाT GTC TTC ATT GCT GGT-3' \\
IE1-right-sense & 5'-GGG CTG CAG AGC CAA AGA TGG CAT ATT GGG-3' \\
IE1-right antisense & 5'-CCC AAG CTT CAA TाT CTT CAT TCC AAA CAC-3' \\
IE1-Nhel-sense & 5'-CCC GCT AGC CCA CC ATG GCC AGT AAA GAC T-5' \\
IE1-BamHI-anti & 5'-CCC GGA TCC TCA TGT CCT GAG TGG GTC TAT \\
& GTT-3' \\
Smal-Asel-Kana & 5'- AAC CCC CGG GAT TAA TCC GGA ATT GCC AGC \\
sense & TGG GG-3' \\
Smal-Mlul-Kana & 5'-CCA ACC CGG GAC GCG TGA AAT TGT AAG CGT \\
anti & TAA TAA T-3' \\
BST2sense-ECoRV & 5'-CCC GAT ATC CCACC ATG GAT TAC AAG GAT \\
& GAC-3' \\
BST2anti-Nhel & 5'-CCC GCT AGC TCA GGT CAG CAG AGC GTT GAG \\
& GAC-3'
\end{tabular}

with the unique ability to restrict the egress of some enveloped viruses [21], was counteracted in terms of viral egress restriction activity in the presence of $\mathrm{K} 5$ [22]. More recently, it was demonstrated that, similar to other K5 targets, BST-2 is ubiquitinated by K5, resulting in ubiquitinmediated endocytosis and lysosomal destruction [23]. Starting from these information the potential BoHV-4IE1 counteracting properties toward BST-2 were investigated. For this purpose a cell line, BEK-boBST-2, over expressing bovine BST-2 (boBST-2) was generated by stably transfecting BEK cells with a bicistronic construct, pCMVboBST-2-IRES-neo, delivering a FLAG tagged boBST-2 ORF (Fig. 4a). G418 selected BEK-boBST-2 cells stably overexpressed boBST-2, as shown by western immunoblotting with a monoclonal antibody directed against the FLAG tag (Fig. 4b). The over-expression of boBST-2 in BEK cells and the deletion of IE1 in BoHV-4 genome should amplify the BoHV-4AIE1 phenotype, in terms of restriction release of BoHV-4 $\triangle I E 1$ IRVPs into the infected BEK-boBST-2 cells supernatant, if BoHV-4IE1 was a real BST-2 counteracting factor. Therefore, the replication kinetics of BoHV-4 $\triangle \mathrm{IE} 1$ and BoHV-4 were compared on BEK-boBST-2, BEK/IE1 and BEK cells. However no significant viral titer decrease at 72 hs post infection for BoHV-4AIE1 infected BEK-boBST-2 cells supernatant respect to that of BoHV-4 infected BEK-boBST-2 cells supernatant (Fig. 4c) was detected. This 1 log viral titer difference remained equal to that revealed for BoHV$4 \triangle \mathrm{IE} 1$ and BoHV-4 infected BEK cells supernatants (Fig. 2b). Moreover, noteworthy a paradoxical significant increase of the viral titer, at 48 hs post infection, for BoHV-4AIE1 infected BEK-boBST-2 cells supernatant respect to the supernatant of BoHV-4 $\triangle \mathrm{IE} 1$ infected BEK

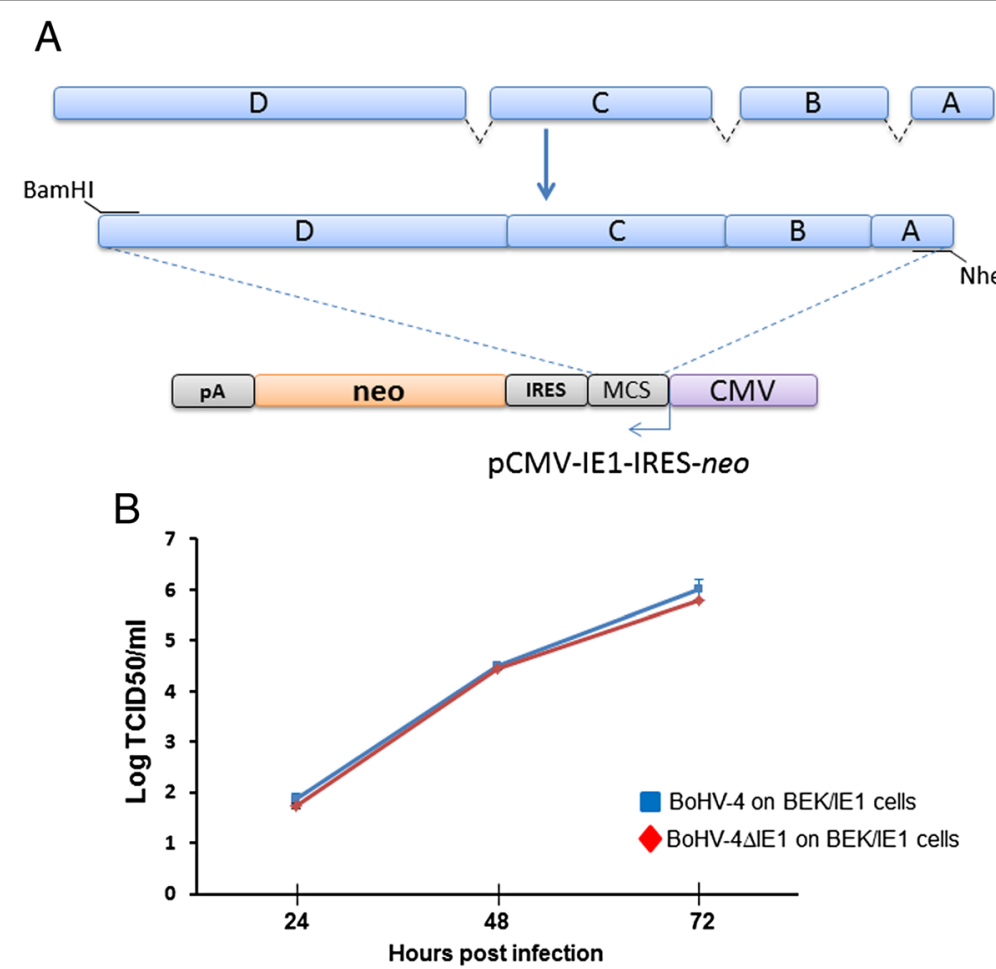

Fig. 3 Rescue of BoHV-4- $\Delta \mid E 1$ impaired replication in trans. a Schematic diagram (not on scale) of BoHV-4IE1 gene containing exons (A, B, C and D) and introns (dashed lines), along with its reverse transcribed CDNA, amplified by PCR with a couple of primers containing restriction sites and to allow its subcloning into the bicistronic vector. b Replication kinetics of BoHV-4AIE1 (red line) and BoHV-4 (blue line) on BEK/E1 cells 


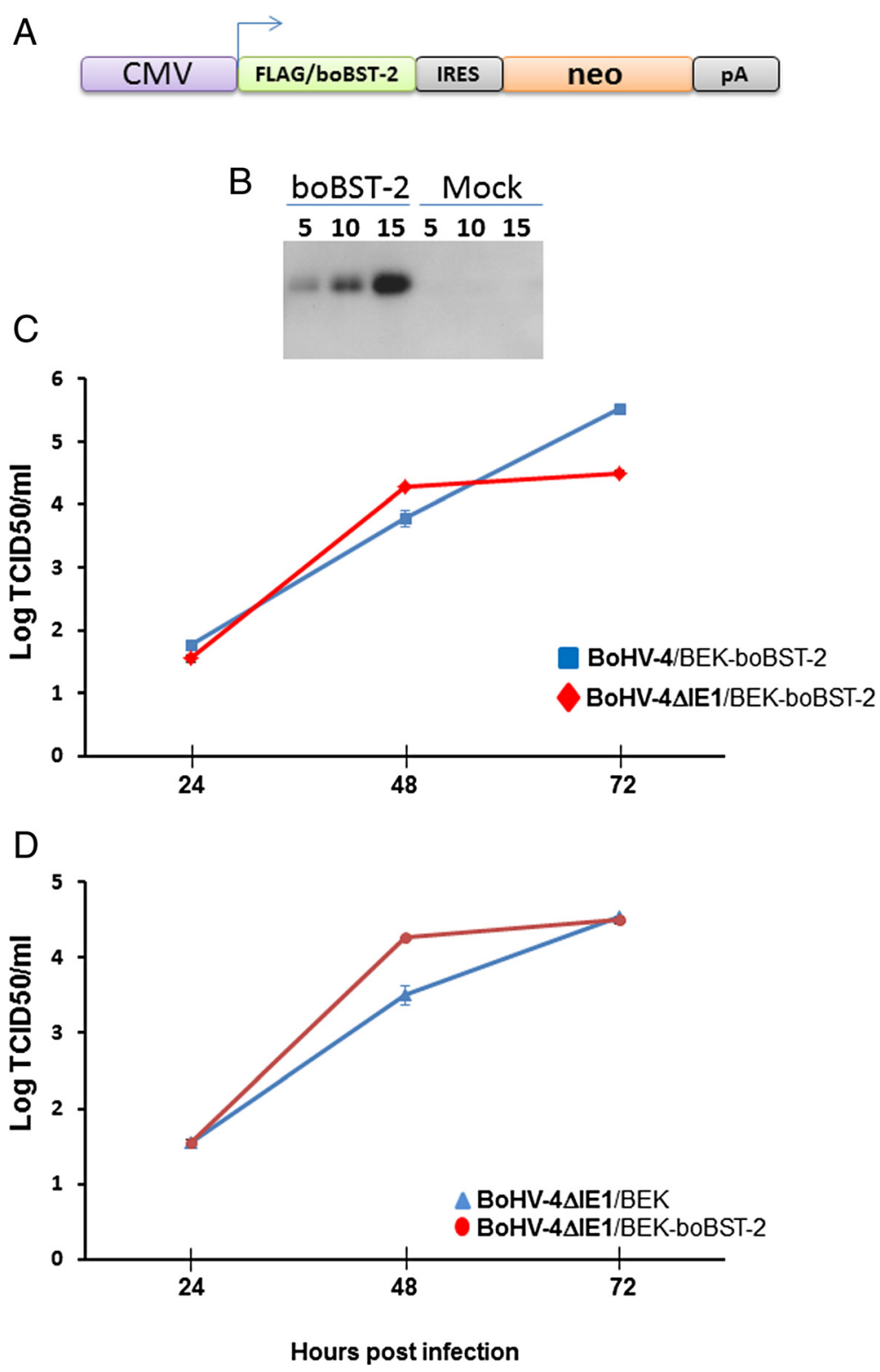

Fig. 4 BoHV-4IE1 is not a tethering counteracting factor. a Schematic diagram (not on scale) of the bicistronic construct pCMV-boBST-2-IRES-neo containing the CMV promoter (violet), the flag tagged boBST-2 (green) ORF, an internal ribosomal entry site (IRES; grey), the neo ORF (orange) and a polyadenilation signal (pA; grey). b Western immunoblotting of BEK cells stably transfected with pCMV-boBST-2-IRES-neo (BEK-boBST-2 ) and selected with G418. The lanes were loaded with different amounts of total protein cell extract $(5,10$ and $20 \mu \mathrm{g})$. Negative control was established with empty vector transfected cells (Mock). c Replication kinetics of BoHV-4LIE1 (red line) and BoHV-4 (blue line) on BEK-boBST-2 cells. d Replication kinetics of BoHV-4AIE1 made on BEK cells (blue line) and compared to that made on BEK-boBST-2 cells (red line)

cells (Fig. 4d) was observed. Although this last data was not further investigated, it could be assumed a role different than a BST-2 counteraction factor for BoHV-4IE1 gene product. On the other hand the similarities observed in silico between $\mathrm{K} 5$ and BoHV-4IE1 were very mild and limited to the amino-terminal portion of the proteins (Additional file 1). This could justify the lack of functional similarity in terms of BST-2 counteracting activity observed for IE1 and represents a classical demonstration that the in silico prediction should be always experimentally verified before to draw any conclusion.

\section{Conclusions}

BoHV-4 has been suggested as a vector for gene delivery $[15,16,19,24-27]$. Several molecular and biological characteristics for this virus include: absence of oncogenicity, ability to accommodate large amounts of foreign genetic material, ability to be maintained in an episomal state in 
dividing cells and capability to infect several cellular types derived from different animal species. Although the genome of BoHV-4 has been sequenced completely $[9,28]$ the functional importance of most of the genes remains unknown. Targeting genes and regions of gene expression regulation and the phenotypic analysis of the BoHV-4 mutants represents a powerful tool to study the direct and indirect interactions of genes and genomic elements in a biological context. The classification of equivalent phenotypes carrying different types of mutations will provide insight into functional networks and their constituting elements. Fewer than 75-80 ORFs have been characterized in BoHV-4, based on amino acids homology and genome location and most of the genes have no apparent homology to known viral or cellular genes. Essential genes are of particular importance and the inactivation of at least one of them is required to create replication-incompetent herpesvirus vectors for vaccination or gene therapy, while non-essential genes can be removed to gain space for insertion of therapeutic genes or generate attenuated vaccines, as it the case of IE1 investigated in the present work. Therefore, these data are extremely valuable when virus genomes, such as BoHV-4, are modified for vector purposes.

\section{Methods \\ Cells}

Bovine embryo kidney [(BS CL-94) BEK, from M. Ferrari, Istituto Zooprofilattico Sperimentale, Brescia, Italy], Madin Darby Bovine Kidney (MDBK, ATCC: CCL-22), African green monkey kidney epithelial cells [(VERO, ATCC: CCL-81) kindly provided by Professor S. Trees, University of Liverpool], BEK expressing cre recombinase (BEKcre) cells [16] and HEK [Human Embryo Kidney 293 T cells [(HEK 293 T) ATCC: CRL-11,268] were cultured in EMEM (Lonza) containing 10 \% FBS, 2 mM Lglutamine (SIGMA), $100 \mathrm{IU} / \mathrm{mL}$ penicillin (SIGMA) and $100 \mathrm{mg} / \mathrm{mL}$ streptomycin (SIGMA) and $2.5 \mathrm{mg} / \mathrm{mL}$ amphotericin B.

\section{Plasmids generation and PCR reactions}

pFlagbovTeth [29] was linearized with PvuI restriction enzyme digestion and used as a template to amplify flagged bovine tetherin ORF. The amplification was carried over 35 cycles, each cycle consisting of denaturation at $94{ }^{\circ} \mathrm{C}$ for $1 \mathrm{~min}$, primer annealing at $55^{\circ} \mathrm{C}$ for $1 \mathrm{~min}$, and chain elongation with $2 \mathrm{U}$ of Pfu DNA polymerase (Thermoscientific) at $72{ }^{\circ} \mathrm{C}$ for $40 \mathrm{~s}$. PCR amplification was carried out in a final volume of $50 \mu \mathrm{L}$ of $10 \mathrm{mM}$ Tris-hydrochloride $\mathrm{pH} 8.3$ containing $0.2 \mathrm{mM}$ deoxynucleotide triphosphates, $3 \mathrm{mM} \mathrm{MgCl} 2,50 \mathrm{mM} \mathrm{KCl}, 5 \%$ dimethyl sulfoxide (DMSO) and $0.25 \mu \mathrm{M}$ of each primer [BST2 sense-EcoRV and BST2 -anti-NheI primers (Table 1)]. The $\sim 600$ bp PCR amplicon product was checked by sequencing and then subcloned in the expression vector pIres2neo (Clontech), cut with NheI/EcoRV, to generate pCMV-boBST-2-IRES-neo.

To generate pCMV-IE1-IRES-neo, BoHV-4IE1 ORF cDNA was amplified by PCR from reverse transcribed total RNA of BoHV-4 infected BEK cells, using the Ready to Go system (Amersham), according to the manufacturer's instructions. The PCR was performed using IE1-NheI-sense and IE1-BamHI-antisense primers (see Table 1) over 35 cycles, each cycle consisting of denaturation at $94{ }^{\circ} \mathrm{C}$ for $1 \mathrm{~min}$, primer annealing at $58{ }^{\circ} \mathrm{C}$ for $1 \mathrm{~min}$, and chain elongation with $2 \mathrm{U}$ of Pfu DNA polymerase (Thermoscientific) at $72{ }^{\circ} \mathrm{C}$ for $1 \mathrm{~min}$. The amplification was carried out in a final volume of $50 \mu \mathrm{L}$ of $10 \mathrm{mM}$ Tris-hydrochloride $\mathrm{pH} 8.3$ containing $0.2 \mathrm{mM}$ deoxynucleotide triphosphates, $3 \mathrm{mM} \mathrm{MgCl}, 50 \mathrm{mM}$ $\mathrm{KCl}, 5 \% \mathrm{DMSO}$ and $0.25 \mu \mathrm{M}$ of each primer. The 900 bp IE1 ORF cDNA amplicon was then cut with $\mathrm{NheI}$ /BamHI and inserted in an expression vector, pIres2neo (Clontech) cut with the same enzymes.

To amplify Immediate Early 1 homology arm regions one microgram of pBAC-BoHV-4 DNA sample was amplified over 35 cycles, each cycle consisting of denaturation at $94{ }^{\circ} \mathrm{C}$ for $1 \mathrm{~min}$, primer annealing at $56^{\circ} \mathrm{C}$ for $1 \mathrm{~min}$, and chain elongation with $2 \mathrm{U}$ of Pfu DNA polymerase (Thermoscientific) at $72{ }^{\circ} \mathrm{C}$ for $2 \mathrm{~min}$. PCR amplification was carried out in a final volume of $50 \mu \mathrm{L}$ of $10 \mathrm{mM}$ Tris-hydrochloride $\mathrm{pH} 8.3$ containing $0.2 \mathrm{mM}$ deoxynucleotide triphosphates, $3 \mathrm{mM} \mathrm{MgCl}, 50 \mathrm{mM}$ $\mathrm{KCl}, 5 \% \mathrm{DMSO}$ and $0.25 \mu \mathrm{M}$ of each primer. The primers used to amplify BoHV-4IE1 left and right arms, were IE1left-sense and antisense (introducing a EcoRI site in the sense primer and a KpnI site in the antisense) and IE1right-sense and antisense (inserting a PstI site in the sense primer and a HindIII in the antisense primer) (see Table 1). The so generated 938 and 992 bp amplicons (respectively for the left and the right arms) were then checked in $1 \%$ agarose gel and visualized after ethidium bromide staining in $1 \times$ TAE buffer (40 mM Tris-acetate, $1 \mathrm{mM}$ EDTA) and used to subclone the IE1 left and right homology arm regions in an expression vector. The specificity of the PCR products were determined by sequencing.

The 938 and 992 bp BoHV-4IE1 left and right arm amplicons were firstly inserted in pJET1.2, a commercial vector from Thermoscientific, designed to directly subclone blunt-ended PCR amplicons (as those generated by Pfu polymerase amplification), using the CloneJet PCR Cloning Kit (Thermoscientific), generating pJET/IE1left and PJET/IE1 right.

pTZ-KanaGalK was generated by sub-cloning the 2232 bp galactokinase prokaryotic expression cassette (GalK), along with the kanamycin resistant expression cassette (Kana), into the pTZ57R/T shuttle vector, cut with KpnI/PstI [30]. The targeting vector, pIE1L-KanaGalK- 
IE1R, was generated firstly by the insertion of the $930 \mathrm{bp}$ left IE1 arms, excised from pJET/IE1left, cut with EcoRI/ KpnI, in pTZ-KanaGalK, cut with the same enzymes; in this intermediate construct, cut with PstI/HindIII, was consequently subcloned the 983 bp right IE1 arm, obtained from PJET/IE1right, cut with the same enzymes.

\section{Stable cell lines generation}

BEK cells from a sub-confluent $75 \mathrm{~cm}^{2}$ flask were electroporated (Equibio apparatus; $270 \mathrm{~V}, 1500 \mu \mathrm{F}$ ) with $10 \mu \mathrm{g}$ of pCMV-IE1-IRES-пео DNA in Dulbecco's Modified Eagle Medium with high glucose (DMEM high) without FBS. Electroporated cells were transferred to new $75 \mathrm{~cm}^{2}$ flasks and fed with complete medium (EMEM containing $10 \%$ FBS, $100 \mathrm{IU} / \mathrm{mL}$ of penicillin, $100 \mathrm{mg} / \mathrm{mL}$ streptomycin, $2.5 \mathrm{mg} / \mathrm{mL}$ amphotericin $\mathrm{B}$, and $2 \mathrm{mM}$ L-glutamine). Twenty-four hours after electroporation, stably transfected cells were selected with $700 \mu \mathrm{g} / \mathrm{mL}$ of G418 (Sigma) until visible colonies appeared on the surface of the flask. Some selected clones were independently growth for 20 passages in the presence of G418. Thus, BEK stably expressing IE1 cDNA, BEK/IE1, were obtained.

BEK cells from a sub-confluent $75 \mathrm{~cm}^{2}$ flask were also transfected through electroporation (Equibio apparatus; $270 \mathrm{~V}, 1500 \mu \mathrm{F}$ ) with $10 \mu \mathrm{g}$ of pCMV-boBST-2-IRES-neo DNA in DMEM high in the absence of FBS. Electroporated cells were transferred to new $75 \mathrm{~cm}^{2}$ flasks containing complete medium. Twenty-four hours after electroporation, stably transfected cells were selected with $700 \mu \mathrm{g} / \mathrm{mL}$ of G418 (Sigma) until visible colonies appeared on the surface of the flask. The selective pressure of G418 was maintained during the passages and BEK stably expressing the flagged bovine tetherin cDNA, BEK-boBST-2, were generated.

\section{BAC recombineering and selection}

Recombineering was performed as previously described [31] with some modifications. Five hundred microliters of a $32{ }^{\circ} \mathrm{C}$ overnight culture of SW102 containing BACBoHV-4 were diluted in $25 \mathrm{~mL}$ Luria-Bertani (LB) medium with or without chloramphenicol (SIGMA) selection $(12.5 \mu \mathrm{g} / \mathrm{mL})$ in a $50 \mathrm{~mL}$ baffled conical flask and grown at $32{ }^{\circ} \mathrm{C}$ in a shaking water bath to an $\mathrm{OD}_{600}$ of 0.6. Then, $12 \mathrm{~mL}$ were transferred to another baffled $50 \mathrm{~mL}$ conical flask and heat shocked at $42{ }^{\circ} \mathrm{C}$ for exactly $15 \mathrm{~min}$ in a shaking water bath. The remaining culture was left at $32{ }^{\circ} \mathrm{C}$ as the un-induced control. After $15 \mathrm{~min}$ the two samples, induced and un-induced, were briefly cooled in ice/water bath slurry and then transferred to two $15 \mathrm{~mL}$ Falcon tubes and pelleted using 5000 r.p.m. (Eppendorf centrifuge) at $0{ }^{\circ} \mathrm{C}$ for $5 \mathrm{~min}$. The supernatant was poured off and the pellet was resuspended in $1 \mathrm{~mL}$ ice cold $\mathrm{dH} 2 \mathrm{O}$ by gently swirling the tubes in ice/water bath slurry. Subsequently, $9 \mathrm{~mL}$ ice- cold $\mathrm{dH} 2 \mathrm{O}$ were added and the samples pelleted again. This step was repeated once more, the supernatant was removed and the pellet (50 $\mu \mathrm{L}$ each) was kept on ice until electroporated with the gel-purified IE1L-KanaGalK-IE1R fragment obtained by linearizing PIE1L-KanaGalK-IE1R, with HindIII (Thermoscientific). An aliquot of $150 \mathrm{ng}$ of the purified fragment was used for each electroporation in a $0.1 \mathrm{~cm}$ cuvette at $25 \mathrm{mF}, 2.5 \mathrm{kV}$ and $201 \mathrm{~V}$. After electroporation, a recovery of $1 \mathrm{~h}$ of the bacteria in $1 \mathrm{~mL}$ of LB Broth (BD Biosciences) (15 mL Falcon tube) was performed in a $32{ }^{\circ} \mathrm{C}$ shaking water bath. After two washes in sterile M9 salt $\left(6 \mathrm{~g} / \mathrm{L} \mathrm{Na} \mathrm{NPO}_{4}, 3 \mathrm{~g} / \mathrm{L} \mathrm{KH}_{2} \mathrm{PO}_{4}, 1 \mathrm{~g} / \mathrm{L}\right.$ $\mathrm{NH}_{4} \mathrm{Cl}, 0.5 \mathrm{~g} / \mathrm{L} \mathrm{NaCl}$ ) (SIGMA), serial dilutions of the bacteria were plated on M63 minimal medium plates containing $15 \mathrm{~g} / \mathrm{L}$ agar (Invitrogen), $0.2 \% \mathrm{D}$-galactose (SIGMA), $1 \mathrm{mg} / \mathrm{L}$ D-biotin (SIGMA), $45 \mathrm{mg} / \mathrm{L}$ L-leucine (SIGMA) and $12.5 \mathrm{mg} / \mathrm{mL}$ chloramphenicol (SIGMA). Plates were incubated 3 days at $32{ }^{\circ} \mathrm{C}$. Several selected colonies were picked up, streaked on McConkey agar indicator plates (DIFCO, BD Biosciences) containing $1 \% \mathrm{D}$ galactose and $50 \mu \mathrm{g} / \mathrm{mL}$ of kanamycin and incubated at $32{ }^{\circ} \mathrm{C}$ for 3 days until red colonies appeared. Red colonies were grown in duplicate for $5-8 \mathrm{~h}$ in $1 \mathrm{~mL}$ of LB containing $50 \mathrm{mg} / \mathrm{mL}$ of kanamycin (SIGMA) or LB containing $12.5 \mathrm{mg} / \mathrm{mL}$ of chloramphenicol. Only those colonies growing both on chloramphenicol and on kanamycin were kept and grown overnight in $5 \mathrm{~mL}$ of LB containing $12.5 \mathrm{mg} / \mathrm{mL}$ of chloramphenicol. BAC DNA was purified and analyzed through restriction enzyme digestion for IE1L-KanaGalK-IE1R fragment targeted integration. Original detailed protocols for recombineering can also be found at the recombineering website (http:// recombineering.ncifcrf.gov).

\section{Restriction enzyme analysis and non-isotopic Southern hybridization}

Fifteen microliters of BAC DNA prepared from bacteria containing pBAC-BoHV-4 were restriction enzyme digested with PstI, separated by electrophoresis overnight in a $1 \%$ agarose gel, stained with ethidium bromide, capillary transferred to a positively charged nylon membrane (Roche), and cross-linked by UV irradiation by standard procedures. The membrane was pre-hybridized in $50 \mathrm{~mL}$ of hybridization solution ( $7 \%$ SDS, $0.5 \mathrm{M}$ phosphate, $\mathrm{pH}$ 7.2) for $1 \mathrm{~h}$ at $65{ }^{\circ} \mathrm{C}$ in a rotating hybridization oven (Techna instruments). Probe preparation and digoxigenin non-isotopic labelling was performed by PCR. Southern Blotting probe was designed spanning Kana region using the primer pair SmaI-AseI-Kana sense and SmaI-MluIKana anti (see Table 1). PCR amplification was carried out in a final volume of $50 \mu \mathrm{L}$ of $10 \mathrm{mM}$ Tris $-\mathrm{HCl}$, $\mathrm{pH}$ 8.3, containing $0.2 \mathrm{mM}$ deoxynucleotide triphosphates, $0.02 \mathrm{mM}$ alkaline labile digoxigenin-dUTP (deoxyuridine triphosphate) (Roche), $3 \mathrm{mM} \mathrm{MgCl}, 50 \mathrm{mM}$ 
$\mathrm{KCl}$, and $0.25 \mu \mathrm{M}$ of each primer over 35 cycles, each cycle consisting of denaturation at $94{ }^{\circ} \mathrm{C}$ for $1 \mathrm{~min}$, primer annealing at $56{ }^{\circ} \mathrm{C}$ for $1 \mathrm{~min}$, and chain elongation with 1 $\mathrm{U}$ of Taq polymerase (Thermoscientific) at $72{ }^{\circ} \mathrm{C}$ for $1 \mathrm{~min}$. Five microliters of the probe were added to $500 \mu \mathrm{L}$ of $\mathrm{dH}_{2} \mathrm{O}$ into a screw-cap tube, denatured in boiling water for $5 \mathrm{~min}$, and cooled down on ice for another $2 \mathrm{~min}$. Denatured probe was added to $50 \mathrm{~mL}$ of pre-heated $65{ }^{\circ} \mathrm{C}$ hybridization solution [7 \% SDS, $0.5 \mathrm{M}$ phosphate, pH 7.2 and $1 \mathrm{mM}$ ethylenediaminetetraacetic acid (EDTA)] to the pre-hybridized membrane and hybridized overnight at $65{ }^{\circ} \mathrm{C}$ in a rotating hybridization oven (Techna Instruments). Following hybridization, the membrane was washed twice for $30 \mathrm{~min}$ with $100 \mathrm{~mL}$ of washing solution I $(0.5 \times$ SSC $[1 \times$ SSC is $0.15 \mathrm{M} \mathrm{NaCl}$ plus $0.015 \mathrm{M}$ sodium citrate] and $0.1 \%$ SDS) and twice for 30 min with $100 \mathrm{~mL}$ of washing solution II (40 mM phosphate, $\mathrm{pH} 7.2,0.05 \%$ SDS) at $65{ }^{\circ} \mathrm{C}$. On a freshly washed dish, the membrane was incubated for $30 \mathrm{~min}$ at room temperature in $100 \mathrm{~mL}$ of blocking solution (100 mM maleic acid, $\mathrm{pH} 7.5$, $150 \mathrm{mM} \mathrm{NaCl}, 1 \%$ blocking reagent [Roche]). Antidigoxigenin Fab fragment (150 U/200 $\mu \mathrm{L}$ [Roche]), diluted 1:15.000 in $50 \mathrm{~mL}$ of blocking solution, was applied to the membrane for 30 min under gentle shaking at room temperature and washed twice for $15 \mathrm{~min}$ with $100 \mathrm{~mL}$ of washing solution (100 mM maleic acid, $\mathrm{pH} 7.5,150 \mathrm{mM}$ $\mathrm{NaCl}, 0.3$ \% Tween 20). Detection was performed following equilibration of the membrane in detection buffer (100 mM Tris- $\mathrm{HCl}, \mathrm{pH} 9.5,1 \mathrm{mM}$ EDTA) for $2 \mathrm{~min}$ at room temperature. Chemiluminescent substrate (CSPD, Roche) was added by scattering the drops over the surface of the membrane. Signal detection was obtained, exposing the membrane to X-ray film. The exposure time was adjusted with the intensity of the signal.

\section{Cell culture electroporation and recombinant virus reconstitution}

Plasmid BAC DNAs $(5 \mu \mathrm{g})$ in $600 \mu \mathrm{L}$ DMEM without serum were electroporated (Equibio apparatus, $270 \mathrm{~V}$, $960 \mu \mathrm{F}, 4-\mathrm{mm}$ gap cuvettes) into BEK or BEKcre cells from a confluent $25 \mathrm{~cm} 2$ flask. Electroporated cells were then returned to the flask, fed the next day, and split 1:2 when they reached confluence at 2 days post electroporation. Cells were left to grow until Cytopathic Effect (CPE) appeared. Recombinant viruses were propagated by infecting confluent monolayers of BEK and MDBK cells at a multiplicity of infection (m.o.i.) of $0.550 \%$ tissue culture infectious doses (TCID50) per cell and maintaining them in MEM with $10 \%$ fetal bovine serum (FBS) for 2 hs. The medium was removed and replaced by fresh MEM containing $10 \%$ FBS. When approximately $90 \%$ of the cell monolayer exhibited CPE ( 72 h post infection), the virus was prepared by freezing and thawing cells three times and pelleting virions through
$30 \%$ sucrose, as described previously [16]. Virus pellets were resuspended in cold MEM without FBS. TCID50 were determined on MDBK or BEK cells by limiting dilution.

\section{Viruses and viral replication}

Bovine herpesvirus-4 (BoHV-4), BoHV-4ATK [15] and BoHV-4 $\triangle \mathrm{IE} 1$, were propagated by infecting confluent monolayers of VERO, BEK, BEK-IE1 and BEK-boBST2 cells at a multiplicity of infection (m.o.i.) of $0.550 \%$ tissue culture infectious doses (TCID50) per cell and maintained in MEM with $10 \%$ FBS for 2 hs. The medium was then removed and replaced by fresh MEM containing $10 \%$ FBS. When approximately $90 \%$ of the cell monolayer exhibited cytopathic effect (CPE) (approximately 72 hs post-infection), the virus was prepared by freezing and thawing cells three times and pelleting the virions through $30 \%$ sucrose, as described above. Virus pellets were resuspended in cold MEM without FBS. TCID50 were determined in BEK or MDBK cells by limiting dilution. Viruses growth kinetics were assessed infecting BEK, BEK-IE1 and BEK-boBST2 cells with 0.1 m.o.i. of virus, cells were monitored periodically for $72 \mathrm{hs}$ at the microscope to verify the CPE appearance and small aliquots of medium were recovered at 24, 48 and 72 hs and titrated in BEK cells. Viral titer differences between each time point are the averages of triplicate measurements \pm standard errors of the means and were analyzed by analysis of variance (ANOVA).

\section{Viral plaque assay}

VERO cell monolayers were infected with BoHV-4 and BoHV-4 $\triangle \mathrm{IE} 1$ with serial 10-fold dilutions of the viruses and incubated at $37^{\circ} \mathrm{C}$ for 2 hs. Infected cells were then overlaid with fresh $2 \mathrm{X}$ EMEM (4 mM L-glutamine, $200 \mathrm{IU} / \mathrm{mL}$ penicillin, $200 \mathrm{mg} / \mathrm{mL}$ streptomycin, $5 \mathrm{mg} / \mathrm{mL}$ amphotericin B) supplemented with $12 \% \mathrm{FBS}$ and $0,6 \%$ of carboxymethyl-cellulose. Cells were incubated at $37^{\circ} \mathrm{C}$ with a $5 \% \mathrm{CO}^{2}$ atmosphere for $5 \mathrm{ds}$ until the plaques were visible. The medium was discarded and, after a wash with sterile phosphate buffer saline (PBS), the cellular monostrates were fixed in $4 \%$ Paraformaldehyde for $15 \mathrm{~min}$ at room temperature, and stained with $0,5 \%$ crystal violet in absolute ethanol for 5-10 $\mathrm{min}$ at room temperature. Cells were washed with tap water and left to dry at room temperature. The diameter of the plaques was measured through a software for image analysis (AxioVision Rel. 4.6. digital image processing software; Carl Zeiss).

\section{Western immunoblotting}

Cell extracts were obtained from BEK-boBST2 scraped from $25 \mathrm{~cm}^{2}$ confluent flasks at several different passage levels (from 2 nd to 10 th) by adding $100 \mu \mathrm{L}$ of cell extraction buffer $(50 \mathrm{mM}$ Tris- $\mathrm{HCl}, 150 \mathrm{mM} \mathrm{NaCl}$, and 
$1 \% \mathrm{NP}-40 ; \mathrm{pH} 8)$ to cell pellets. Cell extracts containing $50 \mu \mathrm{g}$ of total protein were electrophoresed through sodium dodecyl sulfate-10 \% polyacrylamide gels and transferred to nylon membranes by electroblotting. Membranes were incubated with mouse anti-FLAG M2 monoclonal antibody (1:1000 dilution; F1804; SIGMA), which was detected with horseradish peroxidase-labelled goat anti rabbit immunoglobulin G1 (IgG1) antibody (1:15.000; A0545; Sigma), and visualized by enhanced chemiluminescence (ECL Kit; Pierce).

\section{Statistics}

Data were analyzed using one way analysis of variance (ANOVA) followed by Dunnet's post hoc test for group comparisons. Results are reported as mean \pm SD and significance was attributed when P,0.05 (*) or P,0.01 (**).

\section{Additional file}

\section{Additional file 1: Alignment between KSHV K5 and BoHV-4IE1}

protein sequence. The sequence of KSHV K5 protein was aligned with BoHV-4 Immediate early 1 gene product to highlight the percentage of sequence identities and positive matches through the alignment software BLAST-2 (https://blast.ncbi.nlm.nih.gov/Blast.cgi?PROGRAM= blastp\&PAGE_TYPE=BlastSearch\&BLAST_SPEC=blast2seq\&LINK_LOC= blasttab). (TIFF $5192 \mathrm{~kb}$ )

\begin{abstract}
Abbreviations
VERO: African green monkey kidney epithelial cells; aa: Amino acids; ANOVA: Analysis of variance; BAC: Bacterial artificial chromosome; BEK: Bovine embryo kidney; BEK-boBST-2: BEK expressing bovine tetherin CDNA; BEKcre: BEK expressing cre recombinase; BST-2: Bone marrow stromal cell antigen 2; boBST-2: Bovine BST-2; BoHV-4: Bovine herpesvirus 4; CMV: Cytomegalovirus; CPE: Cytopathic effect; DMSO: Dimethyl sulfoxide; DMEM: Dulbecco's modified eagle medium; dUTP: Deoxyuridine triphosphate; E: Early genes; EDTA: Ethylenediaminetetraacetic acid; EMEM: Eagle's minimum essential medium; FBS: Fetal bovine serum; GalK: Galactokinase; HEK 293 T: Human embryo kidney 293 T cells; IE: Immediate early genes; IgG1: Immunoglobulin G1; IRVPs: Infectious replicating viral particles; IRES: Internal ribosomal entry site; KSHV: Kaposi sarcoma associated herpesvirus; L: Late genes; LAP: Leukemia associated protein; LB: Luria-Bertani medium; MDBK: Madin darby bovine kidney; m.o.i: Multiplicity of Infection; ORFs: Open reading frames; PBS: Phosphate buffer saline; PHD: Plant homeo domain; SDS: Sodium dodecyl sulfate; TAE: TrisAcetate buffer; TK: Thymidine kinase gene; TCID50: Tissue culture infectious doses ${ }_{50}$.
\end{abstract}

\section{Competing interest}

The authors declare that they have no competing interests.

\section{Authors' contributions}

VF performed the experiments and contributed to write the paper; AC, SJ and AR contributed to perform the experiments; SC, FX and WQ provided some reagents; GD conceived and designed the experiments and wrote the paper. All authors read and approved the final manuscript.

\section{Acknowledgements}

We would like to thank the Italian Ministry for Education, University and Research (MIUR), Grant \# 2010LLXR94_004 for the financial support.

\section{Author details}

'Department of Medical-Veterinary Science, University of Parma, via del Taglio 10, 43126 Parma, Italy. ${ }^{2}$ Key Laboratory of Molecular Microbiology and Biotechnology, College of Life Sciences, Nankai University, Tianjin, China.
Received: 11 May 2015 Accepted: 12 August 2015

Published online: 27 August 2015

\section{References}

1. Osorio FA, Reed DE, Rock DL. Experimental infection of rabbits with bovine herpesvirus-4: acute and persistent infection. Vet Microbiol. 1982;7(6):503-13.

2. Osorio FA, Reed DE. Experimental inoculation of cattle with bovine herpesvirus-4: evidence for a lymphoid-associated persistent infection. Am J Vet Res. 1983;44(6):975-80.

3. Frazier KS, Baldwin CA, Pence M, West J, Bernard J, Liggett $A$, et al. Seroprevalence and comparison of isolates of endometriotropic bovine herpesvirus-4. J Vet Diagn Invest. 2002;14(6):457-62.

4. Donofrio G, Herath S, Sartori C, Cavirani S, Flammini CF, Sheldon IM. Bovine herpesvirus 4 is tropic for bovine endometrial cells and modulates endocrine function. Reproduction. 2007;134(1):183-97.

5. Jacca S, Franceschi V, Colagiorgi A, Sheldon M, Donofrio G. Bovine endometrial stromal cells support tumor necrosis factor alpha-induced bovine herpesvirus type 4 enhanced replication. Biol Reprod. 2013;88(5):135.

6. Jacca S, Franceschi V, Agosti M, Cavirani S, Mistretta F, Donofrio G. Interferon Gamma-Mediated BoHV-4 Replication Restriction in Bovine Endometrial Stromal Cells Is Host IDO1 Gene Expression Independent and BoHV-4IE2 Gene Expression Dependent. Biol Reprod. 2014;91(5):112.

7. Donofrio G, Ravanetti L, Cavirani S, Herath S, Capocefalo A, Sheldon IM. Bacterial infection of endometrial stromal cells influences bovine herpesvirus 4 immediate early gene activation: a new insight into bacterial and viral interaction for uterine disease. Reproduction. 2008;136(3):361-6.

8. Donofrio G, Capocefalo A, Franceschi V, Price S, Cavirani S, Sheldon IM. The chemokine IL8 is up-regulated in bovine endometrial stromal cells by the BoHV-4IE2 gene product, ORF50/Rta: a step ahead toward a mechanism for BoHV-4 induced endometritis. Biol Reprod. 2010;83(6):919-28.

9. Zimmermann W, Broll H, Ehlers B, Buhk HJ, Rosenthal A, Goltz M. Genome sequence of bovine herpesvirus 4, a bovine Rhadinovirus, and identification of an origin of DNA replication. J Virol. 2001;75(3):1186-94.

10. Knipe DM, Cliffe A. Chromatin control of herpes simplex virus lytic and latent infection. Nat Rev Microbiol. 2008;6(3):211-21.

11. van Santen VL. Characterization of the bovine herpesvirus 4 major immediate-early transcript. J Virol. 1991;65(10):5211-24.

12. van Santen VL. Characterization of a bovine herpesvirus 4 immediate-early RNA encoding a homolog of the Epstein-Barr virus R transactivator. J Virol. 1993;67(2):773-84

13. Donofrio G, Cavirani S, Taddei S, Flammini CF. Activation of bovine herpesvirus 4 lytic replication in a non-permissive cell line by overexpression of BoHV-4 immediate early (IE) 2 gene. J Virol Methods. 2004; 116(2):203-7.

14. Franceschi V, Capocefalo A, Ravanetti L, Vanderplasschen A, Gillet L, Cavirani S, et al. Bovine herpesvirus 4 immediate early 2 (Rta) gene is an essential gene and is duplicated in bovine herpesvirus 4 isolate $\mathrm{U}$. Vet Microbiol. 2011;148(2-4):219-31.

15. Donofrio G, Sartori C, Ravanetti L, Cavirani S, Gillet L, Vanderplasschen A, et al. Establishment of a bovine herpesvirus 4 based vector expressing a secreted form of the bovine viral diarrhoea virus structural glycoprotein E2 for immunization purposes. BMC Biotechnol. 2007;7:68.

16. Donofrio G, Sartori C, Franceschi V, Capocefalo A, Cavirani S, Taddei S, et al. Double immunization strategy with a BoHV-4-vectorialized secreted chimeric peptide BVDV-E2/BoHV-1-gD. Vaccine. 2008;26(48):6031-42.

17. Capocefalo A, Mangia C, Franceschi V, Jacca S, van Santen VL, Donofrio G. Efficient heterologous antigen gene delivery and expression by a replication-attenuated BoHV-4-based vaccine vector. Vaccine. 2013;31(37):3906-14.

18. Franceschi V, Capocefalo A, Cavirani S, Donofrio G. Bovine herpesvirus 4 glycoprotein $B$ is indispensable for lytic replication and irreplaceable by VSVg. BMC Vet Res. 2013;9:6.

19. Donofrio G, Cavirani S, Simone T, van Santen VL. Potential of bovine herpesvirus 4 as a gene delivery vector. J Virol Methods. 2002;101(1-2):49-61.

20. Fruh K, Bartee E, Gouveia K, Mansouri M. Immune evasion by a novel family of viral PHD/LAP-finger proteins of gamma-2 herpesviruses and poxviruses. Virus Res. 2002;88(1-2):55-69. 
21. Douglas JL, Gustin JK, Viswanathan K, Mansouri M, Moses AV, Fruh K. The great escape: viral strategies to counter BST-2/tetherin. PLoS Pathog. 2010;6(5):e1000913.

22. Bartee E, McCormack A, Fruh K. Quantitative membrane proteomics reveals new cellular targets of viral immune modulators. PLoS Pathog. 2006;2(10):e107.

23. Mansouri M, Viswanathan K, Douglas JL, Hines J, Gustin J, Moses AV, et al. Molecular mechanism of BST2/tetherin downregulation by K5/MIR2 of Kaposi's sarcoma-associated herpesvirus. J Virol. 2009;83(19):9672-81.

24. Donofrio G, Bottarelli E, Sandro C, Flammini CF. Expression of bovine viral diarrhea virus glycoprotein E2 as a soluble secreted form in a Mammalian cell line. Clin Vaccine Immunol. 2006;13(6):698-701.

25. Donofrio G, Franceschi V, Capocefalo A, Taddei S, Sartori C, Bonomini S, et al. Cellular targeting of engineered heterologous antigens is a determinant factor for bovine herpesvirus 4-based vaccine vector development. Clin Vaccine Immunol. 2009;16(11):1675-86.

26. Donofrio G, Franceschi V, Lovero A, Capocefalo A, Camero M, Losurdo M, et al. Clinical protection of goats against CpHV-1 induced genital disease with a BoHV-4-based vector expressing CpHV-1 gD. PLoS One. 2013;8(1):e52758.

27. Donofrio G, Taddei S, Franceschi V, Capocefalo A, Cavirani S, Martinelli N, et al. Swine adipose stromal cells loaded with recombinant bovine herpesvirus 4 virions expressing a foreign antigen induce potent humoral immune responses in pigs. Vaccine. 2011;29(5):867-72.

28. Palmeira L, Machiels B, Lete C, Vanderplasschen A, Gillet L. Sequencing of bovine herpesvirus 4 v.test strain reveals important genome features. Virol J. 2011;8:406.

29. Xu F, Tan J, Liu R, Xu D, Li Y, Geng Y, et al. Tetherin inhibits prototypic foamy virus release. Virol J. 2011:8:198.

30. Donofrio G, Franceschi V, Capocefalo A, Cavirani S, Sheldon IM. Isolation and characterization of bovine herpesvirus $4(\mathrm{BoHV}-4)$ from a cow affected by post partum metritis and cloning of the genome as a bacterial artificial chromosome. Reprod Biol Endocrinol. 2009:7:83.

31. Warming S, Costantino N, Court DL, Jenkins NA, Copeland NG. Simple and highly efficient BAC recombineering using galK selection. Nucleic Acids Res. 2005;33(4):e36.

\section{Submit your next manuscript to BioMed Central and take full advantage of:}

- Convenient online submission

- Thorough peer review

- No space constraints or color figure charges

- Immediate publication on acceptance

- Inclusion in PubMed, CAS, Scopus and Google Scholar

- Research which is freely available for redistribution 